\title{
INTERFACIAL AREA MEASUREMENT METHODS
}

by

M. J. Tan and M. Ishii

Reactor Analysis and Safety Division Argonne National Laboratory Argonne, Illinois 60439

February 1989

\section{REPRODUCED FROU BEST AVALABLE COPY}

Argonne National Laboratory, Argonne, Illinois 60439 operated by The University of Chicago for the United States Department of Energy under Contract W-31-109-Eng-38 
Argonne National Laboratory, with facilities in the states of Illinois and Idaho, is owned by the United States government, and operated by The University of Chicago under the provisions of a contract with the Department of Energy.

\section{DISCLAIMER}

This report was prepared as an account of work sponsored by an agency of the United States Government. Neither the United States Government nor any agency thereof, nor any of their employees, makes any warranty, express or implied, or assumes any legal liability or responsibility for the accuracy, completeness, or usefulness of any information, apparatus, product, or process disclosed, or represents that its use would not infringe privately owned rights. Reference herein to any specific commercial product, process, or service by trade name, trademark, manufacturer, or otherwise, does not necessarily constitute or imply its endorsement, recommendation, or favoring by the United States Government or any agency thereof. The views and opinions of authors expressed herein do not necessarily state or reflect those of the United States Government or any agency thereof.

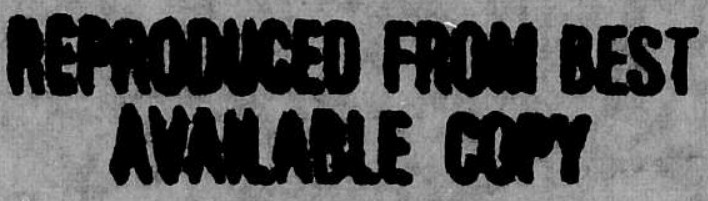

This report has been reproduced from the best available copy.

$$
\text { Available from the }
$$

National Technical Information Service

NTIS Energy Distribution Center

P.O. Box 1300

Oak Ridge, TN 37831

Price: Printed Copy A03

Microfiche A01 
MFRI-4

ANL-89/5

ANL- -89/5

Distribution Category:

DE89 009693

Engineering, Equipment, and Instrumentation

(UC-406)

\title{
INTERFACIAL AREA MEASUREMENT METHODS
}

\author{
b y
}

M. J. Tan and M. Ishii

Reactor Analysis and Safety Division

Argonne National Laboratory

9700 South Cass Avenue

Argonne, Illinois 60439

February 1989

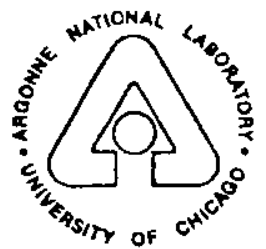

ARGONNE NATIONAL LABORATORY 9700 SOUTH CASS AVENUE ARGONNE, ILLINOIS 60439

(312) $972-5910$

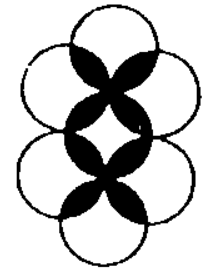

MIDWEST UNIVERSITIES ENERGY CONSORTIUM, INC. POST OFFICE BOX 5478 CHICAGO, ILLINOIS 60680 (312) $\quad 996-4490$

Prepared for U. S. Department of Energy, Office of Basic Energy Sciences 


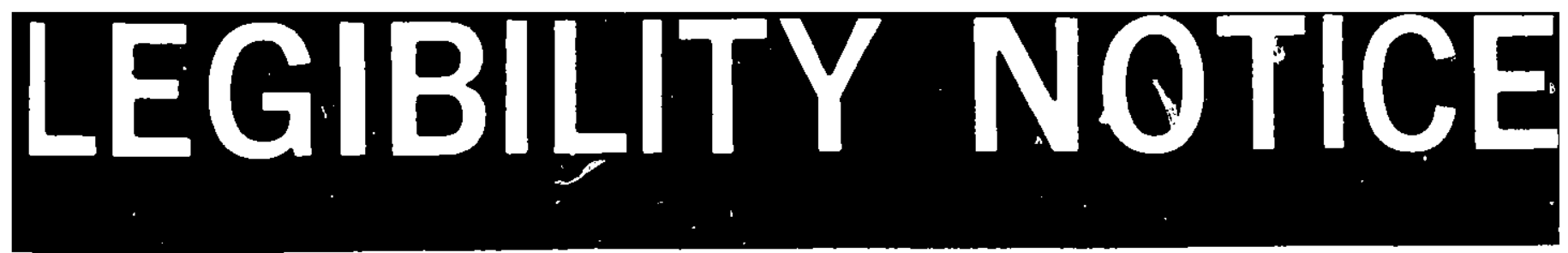

\section{A major purpose of the Techni-} cal Information Center is to provide the broadest dissemination possible of information contained in DOE's Research and Development Reports to business, industry, the academic community, and federal, state and local governments.

\section{Although a small portion of this} report is not reproducible, it is being made available to expedite the availability of information on the research discussed herein. 


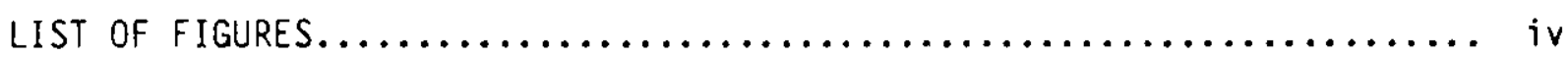

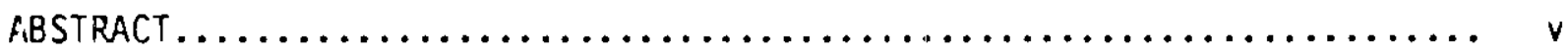

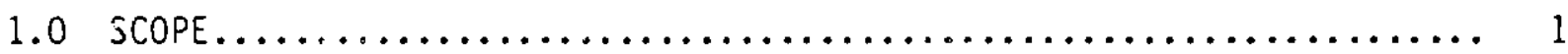

1.1 Interfacial Ärea Modeling........................... 1

1.2 Flow-Pattern Transition Modeling...................... 1

1.3 Modeling of Interfacial Momentum, Mass and Energy Transfer.... 2

2.0 SignificAnCE........................................ 2

3.0 INTRODUCTION.............. ,. $\ldots \ldots \ldots \ldots \ldots \ldots \ldots \ldots \ldots, 3$

$4.0 \quad$ Literature SURVEY............ $\ldots \ldots \ldots \ldots \ldots \ldots \ldots \ldots \ldots$

5.0 PRINCIPLE OF LOCAL MEASUREM. . $\quad \ldots \ldots \ldots \ldots \ldots \ldots \ldots \ldots \ldots, 12$

6.0 TECHNICAL APPROACH............................. 20

7.0 EXPERIMENTAL METHODS................................. 25

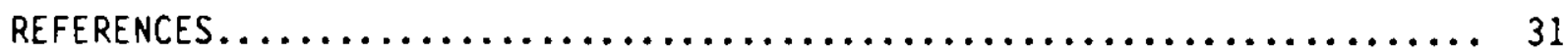


No.

Title

1 Schematic of an Interface Passing Through Two Fixed

Locations in Space................................. 14

2 Schematic of an Interface Passing Through Four Fixed

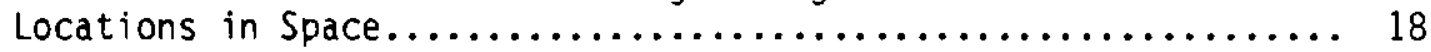

3 Typical Double-Sensor Electrica? Resistivity Probes.......... 22

4 Typical Configuration of Electrical Circuitry in the Electrical-Resistivity-Probe Technique................. 23

5 Typical Time-History Records of Voltage Signals from a Double-Sensor Electrical Res istivity Probe................ 24

6 Illustration of Coordinate System for Probe Traversal Conf iguration..................................... 26

7 Definition of Parameters Pertinent to Data Analysis.......... 28 
by

M. J. Tan and M. Ishii

ABSTRACT

Knowledge of local specific interfacial area is required for analysis and prediction of transient and steady characteristics of two-phase flow systems using the two-fluid models. Based on a survey of published work on the subject of specific interfacial area, it is recognized that there is virtually no data base for local specific interfacial area. This report describes the ongoing development of experimental techniques for measurement of local specific interfacial area in gas-liquid and liquid-liquid two-phase systems. Mathematical relations between local specific interfacial area and measurable quantities are derived based on kinematics and geometry. Two methods for determining local specific interfacial area are identified; both entail detection of passage of interfaces through fixed locations in the flow field. A multiple-sensor electrical-resistivity-probe technique is being developed for determination of local specific interfacial area in vertical gas-liquid bubbly flows. The technique consists of simultaneous measurements at two or four locations in the two-phase flow field of the local electrical resistivity of the two-phase mixture. Methods for data analysis are described. Limitations of the technique are briefly discussed. 


\section{C SCOPE}

The research program is a joint effort by the members of Argonne National Laboratory (ANL) and the University of Wisconsin-Milwaukee. It aims at developing instrumentation techniques, a data base and predictive methods for describing the interfacial structure of horizontal and vertical two-phase flows. The scope of ANL work includes development of local specific interfacial area measurement techniques and development of two-phase flow-pattern transition criteria in vertical two-phase flow systems.

\subsection{Interfacial Area Modeling}

The objective of this task is four-fold. The first is to derive fundamental relations between loca: specific interfacial area and measurable quantities based on kinematics ano geometry. The second is to develop instrumentation techniques for measurement of local specific interfacial area in various two-phase flow patterns eniountered in vertical two-phase flow systems; the fccus is on the bubbly, slug, and churn turbulent flow patterns. The third is to design and perform experiments to generate benchmark data pertinent to local specific interfacial area using well-established optical methods so that the developed local instrumentation techniques can be verified against the benchmark data. The fourth is to develop a reliable model for the specific interfacial area.

\subsection{Flow-Pattern Transition Modeling}

Basic flow patterns observed in a typical vertical two-phase flow system are bubbly, slug or intermittent, churn turbulent and annular. The first objective of this task is to develop flow pattern transition criteria between bubbly and slug, slug and churn turbulent, and churn turbulent and annular flow patterns based on mechanistic modeling. The results can be used for scaling purposes in two-phase flow systems. The second objective is to perform experiments to generate data for flow-pattern transitions using flow visualization techniques. The emphasis is on scaling, developing flow and entrance geometry effects. The third objective is to compare the theoretical and experimental results so as to verify the validity of developed flowpattern transition criteria. 


\subsection{Modeling of Interfacial Momencum, Mass and Energy Transfer}

The objective of this task is to develop constitutive relations for interfacial mass, momentum and energy transfer based on the experimental and analytical results from local specific interfacial area study and from phasic velocity study. The interfacial momentum transfer can be modeled according to the particle size distribution and local drag while modeling of the interfacial mass and energy transfer can follow the hydrodynamic study of interfacial area and momentum transfers.

\subsection{SIGNIFICANCE}

Two-phase flow occurs in a large number of engineering systems as well as in many natural phenomena. Many of the two-phase flow systems have a common structure, i.e., a common topography of the interface. Whereas single-phase flows can be classified according to the geometry of the flow into laminar, transitional and turbulent flow, two-phase flows can be classified according to the geometry of the interface into three main classes: separated flows, transitional or mixed flows and dispersed flows.

It is well established that models for single-phase flow systems are formulated in terms of field equations which describe the conservation laws of mass, momentum, energy, charge, etc. These field equations are then complemented by appropriate constitutive equations such as the constitutive equations of state, stress, chemical reactions, etc., which specify the thermodynamic, transport and chemical properties of the given constituent material. On a rational basis, models which describe the steady state and dynamic characteristics of two-phase flow systems should also be formulated in terms of the appropriate field and closure relations. However, the derivation of such equations is considerably more complicated than that for single-phase flow systems.

The difficulties which are encountered in deriving the field and closure equations appropriate to two-phase flow systems stem from the presence of the interface and the fact that both the steady and transient characteristics of two-phase flow systems depend upon the structure of the flow. In the case of dispersed flows, the steady and the transient characteristics of the flow systems depend on the collective dynamics of solid particles, bubbles or droplets interacting with each other and with the surrounding continuous phase; in 
the case of separated fliws these characteristics depend upon the structure and dynamics of the interface. For example, the performance and flow stability of a condenser for space application depend on the dynamics of the interface. Similarly, the rate of droplet entrainment from a liquid film, and therefore, the effectiveness of film cooling, depend on the stability of the vapor-liquid interface. In order to attain a broad understanding of the thermo-fluid behavior of two-phase flow systems, it is necessary to describe first the local properties of the flow and then to obtain a macroscopic description by means of appropriate averaging procedures. In the case of dispersed flows, for example, it is necessary to determine the rates of nucleation, evaporation or condensation, motion and disintegration of single droplets (bubbles) as well as the collisions and coalescence processes of several droplets (or bubbles).

The design, performance and very often the safe operation of a great number of two-phase flow systems depend on the availability of realistic and accurate field and closure equations. Notwithstanding the fact that the interfacial transfer terms in a two-phase flow formulation play the essential role of describing the interfacial transport of mass, momentum and energy, their modelings are the weakest link in a two-phase flow formulation, owing to considerable difficulties in verification by experimental data. Modeling and verification of flow-pattern transition criteria and interfacial area concentration are thus an important basis for deriving reliable closure relations for two-phase flow models.

\subsection{INTROOUCTION}

A unique feature of two-phase flow systems is the existence of phase interfaces and discontinuity of properties across the interfaces. On the one hand, the internal structures of two-phase flow are characterized by flow patterns. Varicus transfer mechanisms between the two-phase mixture and wall as well as between phases strongly depend on these flow pacterns. This leads to the use of flow-pattern dependent correiations and closure equations together with appropriate flow-pattern transition criteria in two-phase flow analyses. On the other hand, the internal structures of flow are characterized by two fundamental geometrical parameters: the void fraction and the specific interfacial area. The void fraction expresses the phase distribution 
and the specific interfacial area describes available area for the interfacial transfer of mass, momentum and energy.

Various formulations have been proposed to analyze the thermal-hydraulic behavior of two-phase flow. Among these formulations, the two-fluid model [1] considers each phase separately in terms of two sets of conservation equations which govern the balance of mass, momentum, and energy of each phase. These equations represent the balance of macroscopic fields of each phase and are obtained from proper averaging methods. Since the macroscopic fields of one phase are not independent of those of the other phase, the phase interaction terms which couple the transport of mass, momentum, and energy of the tivo phases appear in the field equations. As such, the interfacial transfer terms should be modeled accurately for the two-fluid model to be useful. In the present state of the arts, the closure relations for these interfacial terms are the weakest link in the two-fluid model. The difficulties are due to the complicated transfer mechanisms at the interfaces. To fix ideas, consider the following two-fluid model developed by Ishii [1]

\section{Continuity Equation}

$$
\frac{\partial \alpha_{k} \rho_{k}}{\partial t}+\nabla \cdot\left(a_{k} \rho_{k} \vec{v}_{k}\right)=\Gamma_{k}
$$

\section{Momentum Equation}

$$
\begin{gathered}
\frac{\partial \alpha_{k} \rho_{k} \vec{v}_{k}}{\partial t}+\nabla \cdot\left(a_{k} \rho_{k} \vec{v}_{k} \vec{v}_{k}\right)=-\alpha_{k} \nabla \rho_{k}+\nabla \cdot a_{k}\left(\vec{\tau}_{k}+\tau_{k}^{t}\right) \\
+\alpha_{k} \rho_{k} \vec{g}+\vec{v}_{k j} \Gamma_{k}+\vec{M}_{i k}-\nabla \alpha_{k} \cdot \vec{r}_{i}
\end{gathered}
$$




\section{Enthalpy Energy Equaiion}

$$
\begin{aligned}
\frac{\partial a_{k} \rho_{k} H_{k}}{\partial t} & +\nabla \cdot\left(\alpha_{k} \rho_{k} H_{k} \vec{v}_{k}\right)=-\nabla \cdot \alpha_{k}\left(\overline{\bar{q}}_{k}+q_{k}^{t}\right)+a_{k} \frac{D_{k}}{D t} p_{k} \\
& +H_{k i} \Gamma_{k}+\frac{q_{k i}^{\prime \prime}}{L_{s}}+\phi_{k} .
\end{aligned}
$$

Here $\Gamma_{k}, M_{i k}, \tau_{j}, q_{k i}^{\prime \prime}$, and $\Phi_{k}$ are the mass generation, the generalized interfacial drag, the interfacial shear stress, the interfacial heat flux, and the dissipation, respectively. The subscripts $k$ and $i$ denote phase $k$ and the value at the interface, respectively. $\alpha_{k}, \rho_{k}, v_{k}, p_{k}$ and $H_{k}$ denote the void fraction, the density, the velocity, the pressure and the enthalpy of phase $k$. $\tau_{i}, \tau_{k}^{t}, q_{k}, q_{k}^{t}$ and $g$ denote the average viscous stress, the turbulent stress, the mean conduction heat flux, the turbulent heat flux and the acceleration due to gravity. $H_{k i}$ is the enthalpy of phase $k$ at the interface. $L_{s}$ is a length scale at the interface; $1 / L_{s}$ represents the local timeaveraged specific interfacial area [2]. In this work $1 / L_{s}$ is referred to as the local specific interfacial area.

The interfacial transfer terms, which appear on the right-hand side of Eqs. (1)-(3), are related to each other through the averaged local jump conditions

$$
\begin{aligned}
& \sum_{k} r_{k}=0 \\
& \sum_{k} \vec{M}_{i k}=0 \\
& \sum_{k}\left(r_{k} H_{k i}+q_{k i}^{\prime \prime} / L_{s}\right)=0 .
\end{aligned}
$$

Moreover, closure equations for $M_{i k}, q_{G i}^{\prime \prime} / L_{s}$, and $q_{L i}^{\prime \prime} / L_{s}$ are needed to comp lete the formulation. 
In terms of the mean mass transfer per unit area, $m_{k}$ is defined by

$$
r_{k} \equiv \frac{1}{L_{s}} m_{k} \text {, }
$$

the interfacial energy-transfer term in eq. (3) can be rewritten as

$$
\Gamma_{k} H_{k i}+\frac{q_{k i}^{\prime \prime}}{L_{s}}=\frac{1}{L_{s}}\left(m_{k} H_{k i}+q_{k i}^{\prime \prime}\right) .
$$

The heat flux at the interface can be modeled using the driving force or the potential for an energy transfer as

$$
q_{k i}^{\prime \prime}=h_{k i}\left(T_{i}-T_{k}\right)
$$

where $T_{j}$ and $T_{k}$ are the interfacial and bulk temperatures based on the mean enthalpy and $h_{k j}$ is the interfacial heat transfer coefficient. A similar treatment of the interfacial momentum transfer term is also possible. Thus all interfacial transfer terms in eqs. (1)-(3) can be expressed as the product of the local specific interfacial area and a driving force:

$$
\text { Interfacial transfer term = Driving force } \times \frac{1}{L_{S}} \text {. }
$$

The driving forces are characterized by the local transport mechanisms such as molecular and turbulent diffusions whereas the local specific interfacial area $1 / L_{s}$ is related to the structure of the twc-phase flow field. Knowledge of the loca? specific interfacial area is tius often required for a detailed analys is anc prediction of the behavior of a two-phase flow system.

\subsection{LITERATURE SURVEY}

A variety of methods for measuring specific interfacial areas in gasliquid and liquid-liquid systems have been reported. They can be broadly classified into two categories: chemical methods and physical methods. Before proceeding to a brief survey of these methods, it behooves us to clarify the meaning of the generic term "specific interfacial area" so as to put into perspective comparison between different methods. In addition to the 
local specific interfacial area denoted by $1 / L_{s}$, we speak of the instantaneous volumetric interfacial area $a_{j}(t)$. which is a volume-averaged quantity, and the volumetric interfacial area $\bar{a}_{j}(t)$, which is the time-average of $a_{j}(t)$, i.e.,

$$
\bar{a}_{i}(t)=\frac{1}{T} \int_{t-\frac{T}{2}}^{t+\frac{T}{2}} a_{i}(\tau) d \tau .
$$

The two quantities $1 / L_{s}$ and $a_{i}$ are related to each other by the identity [3]

$$
\bar{a}_{j}=\frac{1}{V} \int_{V} \frac{1}{L_{S}} d \vec{x}
$$

where $V$ denotes the volume relative to which $a_{i}$ is defined. Note that $\vec{a}_{i}=$ $1 / L_{S}$ in case that $1 / L_{S}$ is independent of position in $V$.

The chemical methods, in which a component $A$ in the gas phase is absorbed into the liquid phase where it undergoes a chemical reaction, for which the kinetics are well understood, with a component $B$, have been widely used in connection with the measurements of mass transfer coefficients for bubble columns, stirred tank reactors, and fluidized beds 14-19]. The principle underlying the chemical methods, which have been discussed in detail by Sharma and Danckwerts [20], is summarized as follows.

For an irreversible reaction of a gas phase component $A$ with a liquid phase reactant $B$

$$
A+2 B+\text { products }
$$

which follows a reaction rate law given by

$$
r_{A}=k_{m n} c_{A}^{m} c_{B}^{n} \text {, }
$$

the theory of absorption with chemical reaction [21] predicts that the rate of absorption of $A$ per unit volume of the gas-liquid two-phase mixture, $R_{A}$, is given by 


$$
R_{A}=a_{i} k_{L} c_{A}^{\star} \sqrt{1+M}
$$

provided that

$$
\sqrt{M} \ll 1+\frac{D_{B} C_{B O}}{Z D_{A} C_{A}^{*}}
$$

in which

$$
M=\frac{1}{k_{L}^{2}}\left[\frac{2}{m+1} k_{m n} D_{A}\left(c_{A}^{\star}\right)^{m-1} c_{B O}^{n}\right],
$$

$k_{m n}$ is the rate constant, $c_{A}$ and $c_{B}$ the concentration of $A$ and $B$, respectively, in the liquid phase, $C_{A}$ is the concentration of $A$ at the gas-liquid interface, which is assumed to be equal to the equilibrium concentration of $A$ in the liquid phase, $C_{B o}$ is the concentration of $B$ in the bulk liquid, $z$ is the stoichiometric factor, $D_{A}$ and $D_{B}$ are the diffusion coefficients of $A$ and $B$, respectively, in the liquid phase, and $k_{L}$ is the mass transfer coefficient of $A$ in the liquid phase. In the case of a fast reaction, the condition $\sqrt{M} \gg 1$ is satisfied and eq. (12) can be approximated by

$$
R_{A}=a_{i}\left[\frac{2}{m+1} k_{m n} D_{A}\left(c_{A}^{*}\right)^{m+1} c_{B O}^{n}\right]^{0.5}
$$

In principle, selecting a suitable chemical reaction and measuring the rate of absorption $R_{A}$ as a function of the pseudo rate constant $k_{m}=k_{m n}$ $C_{B O}^{n}$ allows either the instantaneous specific interfacial area $a_{i}$ and the mass transfer coefficient $k_{L}$ to be determined simultaneously from eq. (12) or $a_{j}$ to be obtained directly from eq. (15). Thus knowledge of reaction kinetics, solubility of gas-phase component $A$, diffusion coefficients of $A$ and liquidphase component $B$ in the liquid phase, and experimental capability of measuring the local rate of absorption $R_{A}$ are required for determining $a_{j}$ from eq. (12) or eq. (15). While the chemical systems suitable for the chemical methods have been discussed by Sharma and Danckwerts [20], it is still extremely difficult, if not impossible, to measure directly the local rate of absorption. Hence the chemical methods in practice invariably entail assuming 
steady-state operation and incorporating eq. (12) or eq. (15) into a mass balance on the gas-phase component $A$ followed by integrating the resultant balance equation over the total volume of the test section used in the experiment. Inasmuch as the average of a product usually differs from the product of the averages, the specific interfacial areas thus obtained are effective specific interfacial areas. For bubbly flows, the effective specific interfacial areas are generally smaller than the actual volume-averaged $a_{j}[22]$.

As for the physical methods, three techniques have been used to measure specific interfacial areas in dispersed two-phase flows. They are photography $[7,16,23-26]$, light transmission [7,10,27-29], and ultrasonic pulse transmission $[30-32\}$.

In the photographic technique the instantaneous specific interfacial area $a_{j}$ is evaluated from the volumetric fraction of the dispersed phase $\alpha_{d}$ and the Sauter mean diameter $D_{S}$

$$
a_{i}=\frac{\sum \pi 0_{i}^{2}}{\sum \frac{\pi}{6} 0_{i}^{3} / \alpha_{d}}=\frac{6 \alpha_{d}}{\sum D_{i}^{3} / \sum D_{i}^{2}} \equiv \frac{6 \alpha_{d}}{D_{s}}
$$

where $V$ is the volume over which $a_{j}$ is defined and $D_{j}$ is the diameter of the ith droplet or bubble. For spherical droplets or bubbles this technique gives rather accurate values of the integral specific interfacial areas. In the case of nonspherical droplets or bubbles evaluation of the photographs involves fitting the projected areas of the droplets or bubbles by circles of equal areas, thereby leading to a systematic underestimation of the Sauter diameter and therefore a systematic overestimation of the instantaneous volumetric interfacial areas [16]. In addition, when photographs are taken through a transparent wall, they provide information on conditions near the focal point which may or may not be representative of those over the entire cross section of the experimental apparatus [7].

The method of light transmission is based on the principle that when a collimated light beam is passed through a dispersed two-phase mixture only the part of the beam which does not meet any dispersed phase can reach a detector placed some distance from the light source $\{27,281$. The method of uitrasonic pulse transmission is also based on this principle of energy attenuation $\mid 301$, which is described as follows. 
For a collimated beam of light or a plane wave of ultrasound traveling through a medium, the energy attenuation is generally described by

$$
\ln \frac{I}{I_{0}}=-\alpha L
$$

where $I_{0}$ and I are, respectively, the incident and the transmitted energy, $\alpha$ the attenuation coefficient, and $L$ the path length in the medium. If the energy attenuation is caused by obstacles such as droplets or bubbles, then $\alpha$ is related to the scattering cross sections of the scatterers. Assuming that the individual scatterers are independent of each other, one has [30]

$$
a=\frac{\pi n}{8} \int_{0}^{\infty} S_{a p p}\left(\frac{2 \pi D}{\lambda}\right) D^{2} f(D) d D
$$

where $n$ is the number density of the scatterer, $D$ is the diameter of the scatterer, $f(D)$ is the size distribution of the scatterers, $\lambda$ is the wave length, and $S_{a p p}$ is the apparent scattering coefficient which depends on the real scattering coefficient $S_{n}$ and the geometry of the actual experimental apparatus. Note that by definition

$$
a_{i}=\frac{\pi n}{2} \int_{0}^{\infty} \pi D^{2} f(D) d D .
$$

The theoretical expressions of $S_{n}$ for an air bubble in water have been found by Marston et al. [33] for light scattering and by Nishi [34] for ultrasound scattering. Stravs and von Stockon [30] showed that for a sufficiently large spherical gas bubble, $S_{n}$ approaches 2 for both light and ultrasound scatterings. With light scattering, the diffracted portion of the scattered energy is confined in a very narrow angle so that under normal conditions it will be measured together with the transmitted energy. Thus $S_{a p p}$ is reduced from $S_{n}=2$ to 1. The attenuation coefficient a for light transmission is therefore equal to the projection area of all the bubbles present; this leads to the following relationship between the fraction of incident light transmitted through a dispersion and the specific interfacial area of the dispersion $[27,28\rfloor$ 
$\ln \frac{I}{I_{0}}=-\frac{1}{4} a_{i} L$

It is worth noting that in arriving at eq. (20) it is assumed that there is no interaction between the scattered light, that the dispersed phase is spherical in shape, and that the effects of forward scattering on I are negligible. To justify these assumptions it is necessary to limit the applicability of the light transmission technique to dispersed two-phase flow systems consisting of small droplets or bubbles whose volumetric fractions are less than several percent. The light transmission method for measuring specific interfacial areas in agitated vessels was compared with the chemical method by Sridhar and Potter [10]. It was found that the light transmission method yielded consistently lower values of specific interfacial areas.

In the case of ultrasonic pulse transmission, $S_{a p p}$ depends on the diameters of the dispersed phase and those of the emitting and receiving transducers [30]. When the emitting and receiving transducers are both placed far from the measuring section, one may set $S_{a p p}=S_{n}$ in eq. (18) and make use of eq. (19) to obtain

$$
a_{i}=4 a \frac{\int_{0}^{\infty} D^{2} f(D) d D}{\int_{0}^{\infty} s_{n}\left(\frac{2 \pi D}{\lambda}\right) D^{2} f(D) d D} .
$$

Stravs and von Stockar [30] used simulated size distribution $f(D)$ over a frequency range from 1 to $5 \mathrm{MHz}$ to show that the attenuation coefficient a calculated from

$$
\alpha=\frac{\pi n}{8} \int_{0}^{\infty} S_{n}\left(\frac{2 \pi D}{\lambda}\right) D^{2} f(D) d D
$$

was in the worst case only $3 \%$ greater than that calculated from

$$
\alpha=S_{n}\left(\frac{2 \pi D}{\lambda}\right) \frac{\pi n}{8} \int_{0}^{\infty} D^{2} f(D) d D=\frac{1}{4 L} S_{n}\left(\frac{2 \pi D}{\lambda}\right) \text {. }
$$


It follows that knowing the local Sauter diameter $D_{s}$ one may determine $a_{j}$ from the theoretical value of $S_{n}\left(2 \pi D_{s} / \lambda\right)$ and the measured attenuation coefficient

$$
a=\frac{1}{L} \ln \frac{I}{I_{0}} .
$$

Stravs and von Stockar [30] reported experimental results showing that for gas-liquid dispersions the specific interfacial areas determined with the ultrasonic pulse transmission method differed from those determined with the light transmission method by approximately 5\%. Bensler et al. [32] indicated that the ultrasonic pulse transmission method compared fairly well with the photographic technique in determination of specific interfacial areas in bubbly two-phase flow of low void fraction.

In summary, the chemical methods are the most widely-used techniques for measuring specific interfacial areas. They yield effective values instead of detailed local information. The physica: methods of photography, light transmission, and ultrasonic pulse transmission are applicable to measurement of specific interfacial areas in dispersed two-phase flows. In addition to being limited to dispersed flows, the applicability of the photography method and the light transmission method is restricted to cases in which the walls of flow channel are transparent. The advantages and shortcomings of the various chemical metods and the three physical methods described above have been discussed by Landau et a]. [7] and by Veteau [24].

It should also be mentioned in passing that a technique based on the principle of transmission of short-range beta or alpha particles across interfaces has been proposed by Banerjee and Khachadour [35] for measuring specific interfacial areas in two-component two-phase flows. This technique seems to be applicable only to two-phase flow systems in which one of the two phases is solid.

\subsection{PRINCIPLE OF LOCAL MEASUREMENT METHODS}

According to Ishii [1], the time-average of the specific interfacial area at a fixed position in space $\vec{x}_{0}$ is given by

$$
\frac{1}{L_{s}}=\frac{1}{T} \sum_{j=1}^{N} \frac{1}{\left|\vec{v}_{i j} \cdot \vec{n}_{j}\right|}
$$


where $T$ is the length of the time interval over which the time averaging is considered, $N$ is the number of times over the averaging period $T$ an interface passes through $\vec{x}_{0}, \vec{v}_{i}$ and $\vec{n}$ are the velocity and outward-directed unit normal, respectively, of an interface at $\vec{x}_{0}$.

Let $f(\vec{x}, t)=0$, where $f$ is a scalar field defined on the space-time domain, the Cartesian product of a bounded convex domain in space and the segment of the time domain $-T / 2<t<T / 2$, represent an interface. We say that an event occurs at $\vec{x}_{0}$ when an interface passes through $\vec{x}_{0}$ and, bearing in mind that an iriterface can pass through $\vec{x}_{0}$ more than once, associate the interface represented by $f_{j}\left(\vec{x}_{0}, t_{0 j}\right)=0$ with the one which pertains to the $j$ th time an event occurs at $\vec{x}_{0}$.

Suppose that this jth interface passes through an adjacent fixed point in space $\vec{x}$, at time $t_{1 j}$, as shown in Fig. 1. When the distance $s_{1} \equiv\left|\vec{x}_{1}-\vec{x}_{0}\right|$ and the time difference $\Delta t_{1 j} \equiv t_{1 j}-t_{0 j}$ are small compared to the length scale and the time scale, respectively, we have

$$
\begin{aligned}
f_{j}\left(\vec{x}_{1}, t_{1 j}\right) & =f_{j}\left(\vec{x}_{0}, t_{o j}\right)+s_{1} \nabla f_{j}\left(\vec{x}_{0}, t_{0 j}\right) \cdot \vec{\xi}_{1}+\Delta t_{1 j} \frac{\partial f}{\partial t}\left(\vec{x}_{0}, t_{o j}\right) \\
& + \text { higher order terms },
\end{aligned}
$$

where $\nabla f_{j}\left(\vec{x}_{0}, t_{0 j}\right) \cdot \vec{\xi}_{1}$ denotes the directional derivative of $f_{j}$ in the direction of the unit vector $\vec{\xi}_{1}$ which is parallel to the line passing through $\vec{x}_{0}$ and $\vec{x}_{1}$. It follows that

$$
\frac{s_{1}}{\Delta t_{1 j}}=-\frac{\frac{\partial f_{j}}{\partial t}\left(\vec{x}_{o}, t_{o j}\right)}{\nabla f_{j}\left(\vec{x}_{0}, t_{0 j}\right) \cdot \vec{\xi}_{1}}=-\frac{\frac{\partial f_{j}}{\partial t}\left(\vec{x}_{0}, t_{0 j}\right)}{\left|\nabla f_{j}\left(\vec{x}_{0}, t_{o j}\right)\right| \vec{n}_{j}\left(x_{0}, t_{0 j}\right) \cdot \vec{\xi}_{1}} .
$$

Upon taking the material derivative of $f_{j}$ at $\left(\vec{x}_{0}, t_{0 j}\right)$, we get 


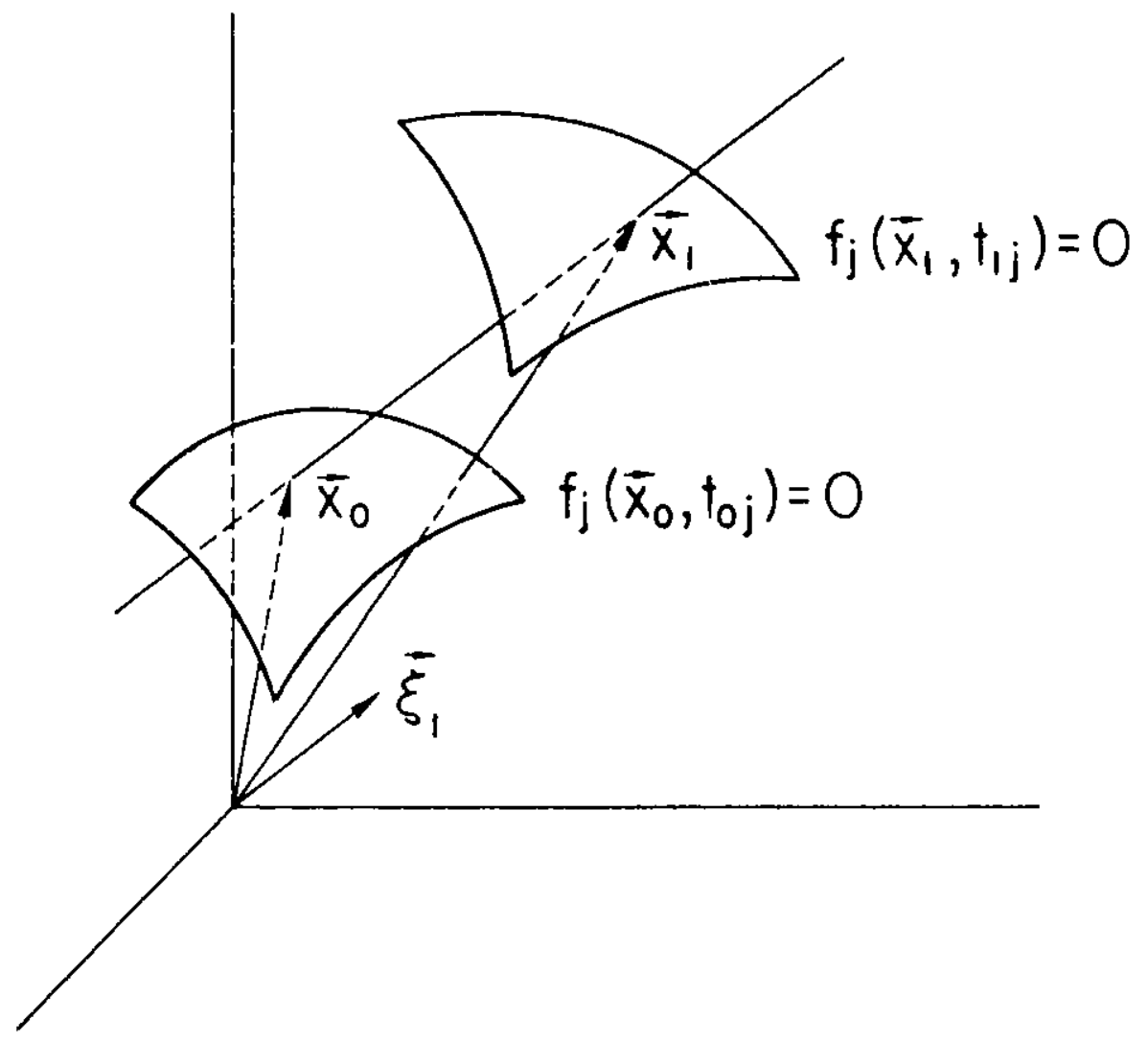

Fig. 1. Schematic of an Interface Passing Through Two Fixed Locations in Space 


$$
\vec{v}_{i j}\left(\vec{x}_{o}, t_{o j}\right) \cdot \vec{n}_{j}\left(\vec{x}_{o}, t_{o j}\right)=-\frac{\frac{\partial f}{\partial t}\left(\vec{x}_{0}, t_{o j}\right)}{\left|\nabla f_{j}\left(\vec{x}_{0}, t_{o j}\right)\right|} .
$$

Combining eq. (2:7) with eq. (28) yie ds

$$
\frac{1}{\vec{v}_{i j}\left(\vec{x}_{0}, t_{0 j}\right) \cdot \vec{n}_{j}\left(\vec{x}_{0}, t_{o j}\right)}=\frac{\Delta t_{1 j}}{s_{1}} \frac{1}{\vec{n}_{j}\left(\vec{x}_{0}, t_{o j}\right) \cdot \vec{\xi}_{1}} .
$$

Substitution of eq. (29) into eq. (25) for $1 /\left(\vec{v}_{i j} \cdot \vec{n}_{j}\right)$ then gives

$$
\frac{1}{L_{s}}=\frac{1}{s_{1}} \frac{1}{T} \sum_{j=1}^{N} \frac{\Delta t_{1 j}}{\left|\vec{n}_{j}\left(\vec{x}_{0}, t_{0 j}\right) \cdot \vec{\xi}_{1}\right|} .
$$

If one assumes that the quantities $\Delta t_{1 j}$ and $1 /\left(\vec{n}_{j}\left(\vec{x}_{0}, t_{0 j}\right) \cdot \vec{\xi}_{1}\right)$ have no correlation statistically, eq. (30) can be rewritten as

$$
\frac{1}{L_{s}}=\frac{1}{s_{1}} \frac{1}{T} \sum_{j=1}^{N} \Delta t{ }_{1 j} \cdot \frac{1}{N} \sum_{j=1}^{N} \frac{1}{\left|\vec{n}_{j}\left(\vec{x}_{0}, t_{0 j}\right) \cdot \vec{\xi}_{1}\right|}
$$

Let $\xi_{1 x}, \xi_{1 y}, \xi_{1 z}$ be the rectangular cartesian components of $\vec{\xi}_{1}$ and $\theta_{j}$, $\phi_{j}$ be the angles between $\vec{n}_{j}$ and $z$-axis, and tietween $\vec{n}_{j}$ and $x$-axis, respectively. Then the term enclosed within the brackets on the right-hand side of eq. (31) can be expressed as

$$
\frac{1}{N} \sum_{j=1}^{N} \frac{1}{\left|\vec{n}_{j}\left(\vec{x}_{0}, t_{0 j}\right) \cdot \vec{\xi}_{1}\right|}=\frac{1}{N} \sum_{j=1}^{N} \frac{1}{\left|\xi_{1 x} \sin \theta_{j} \cos \phi_{j}+\xi_{1 y} \sin \theta_{j} \sin \phi j+\xi_{1 z} \cos \theta_{j}\right|}
$$

If one makes the additional assumption that the summation in eq. (32) can be approximated by 


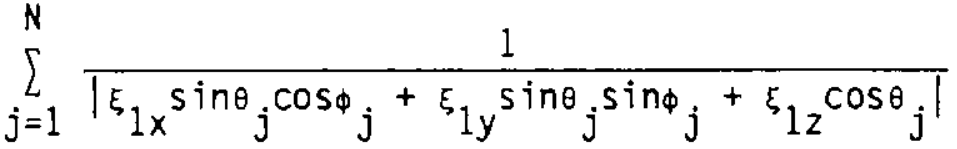

$$
\begin{aligned}
& =\int_{0}^{2 \pi} \int_{0}^{\pi} \frac{P(\theta, \phi) N}{\left|\xi_{1 x} \sin \theta \cos \phi+\xi_{1 y} \sin \theta \sin \phi+\xi_{1 z} \cos \theta\right|} d \theta d \phi
\end{aligned}
$$

where $P(\theta, \phi)$ represents a probability density function of the orientations of the interfaces at $\vec{x}_{0}$, then the local specific area is given by the following expression:

$$
\frac{1}{L_{s}}=\frac{1}{s_{1}} \frac{1}{T} \sum_{j=1}^{N} \Delta t_{1 j} \cdot \int_{0}^{2 \pi} \int_{0}^{\pi} \frac{P(\theta, \phi)}{\left|\xi_{1 x} \sin \theta \cos \phi+\xi_{1 y} \sin \theta \sin \phi+\xi_{1 z} \cos \theta\right|} d \theta d \phi .
$$

Equation (34) suggests that $1 / L_{s}$ can be calculated from seasured values of $\Delta t_{1 j}$ provided that the probability density function $P(\theta, \phi)$ is known. Inasmuch as the orientations of the interfaces at $\vec{x}_{0}$ are necessarily functions of the flow regime under study, a general theory on the form of $P(\theta, \phi)$ seems impossible. This lack of knowledge of $P(\theta, \phi)$ severely precludes the applicability of eq. (34) from all but the particular case of bubbly flow where the shape of the bubbles is spherical. In this particular case, an analytical expression for $P(\theta, \phi)$ is readily found to be

$$
P(\theta, \phi) d_{\theta} d_{\phi}=\frac{1}{\frac{\pi}{4} D^{2}} \cdot \frac{D}{2} \sin \theta d_{\phi} \cdot \frac{D}{2}|\cos \theta| d \theta=\frac{1}{\pi} \sin \theta|\cos \theta| d_{\theta} d_{\phi}
$$

where $D$ is the diameter of a bubble. One can then choose $\vec{\xi}_{1}=\vec{e}_{z}$ so that $\xi_{1 x}$ $=\xi_{1 y}=0$ and $\xi_{1 z}=1$. Hence

$$
\frac{1}{L_{s}}=\frac{1}{s_{1}} \frac{1}{T} \sum_{j=1}^{N} \Delta t_{1 j} \cdot \int_{0}^{2 \pi} \int_{0}^{\pi} \frac{1}{\pi} \sin \theta d \theta d \phi=\frac{4}{s_{1}} \frac{1}{T} \sum_{j=1}^{N} \Delta t_{1 j},
$$

indicating that $1 / L_{s}$ can be determined from measured values of $\Delta t_{1 j}$ alone. 
We now consider the configuration shown in Fig. 2 and suppose that the ith interface passes through the three fixed points $\vec{x}_{1}, \vec{x}_{2}$, and $\vec{x}_{3}$ adjacent to $\vec{x}_{0}$ at times $t_{1 j}, t_{2 j}$, and $t_{3 j}$, respectively. When the distances $s_{k} \equiv \mid \vec{x}_{k}-$ $\vec{x}_{0} \mid(k=1,2,3)$ and the time differences $\Delta t_{k j} \equiv t_{k j}-t_{0 j}(k=1,2,3)$ are small in comparison with the length scale and the time scale, respectively, we again have

$$
\vec{n}_{j}\left(\vec{x}_{0}, t_{0 j}\right) \cdot \vec{\xi}_{k}=-\frac{\frac{\partial f_{j}}{\partial t}\left(\vec{x}_{o}, t_{0 j}\right)}{\left|\nabla f\left(\vec{x}_{0}, t_{0}\right)\right|} \cdot \frac{\Delta t_{k j}}{s_{k}}, \quad k=1,2,3
$$

where $\vec{\xi}_{k}$ is the unit vector parallel to the line passing through $\vec{x}_{0}$ and $\vec{x}_{k}$ $(k=1,2,3)$. In terms of the rectangular cartesian components $\xi_{k x}, \xi_{k y}$, and $\xi_{k z}$ of $\vec{\xi}_{k}$ and the direction cosines $\cos \alpha_{j}, \cos \beta_{j}$ and $\cos \gamma_{j}$ of $\vec{n}_{j}$, eq. (37) can be rewritten as

$$
\xi_{k x} \cos \alpha_{j}+\xi_{k y} \cos \beta_{j}+\xi_{k z} \cos \gamma_{j}=-\frac{\frac{\partial f}{\partial t}\left(\vec{x}_{0}, t_{0 j}\right)}{\left|\nabla f_{j}\left(\vec{x}_{0}, t_{0}\right)\right|} \cdot \frac{\Delta t_{k j}}{s_{k}}, \quad k=1,2,3 .
$$

When the three unit vectors $\vec{\xi}_{1}, \vec{\xi}_{2}$, and $\vec{\xi}_{3}$ are linearly independent, eq. (38) can be solved to give

$$
\begin{aligned}
& \cos {\alpha_{j}}_{j}=-\frac{\frac{\partial f}{\partial t}\left(\vec{x}_{0}, t_{0}\right)}{\left|\nabla f_{j}\left(\vec{x}_{0}, t_{0}\right)\right|} \cdot \frac{A_{1 j}}{A_{0}} \\
& \cos \beta_{j}=-\frac{\frac{\partial f}{\partial t}\left(\vec{x}_{0}, t_{0}\right)}{\left|\nabla f\left(\vec{x}_{0}, t_{0}\right)\right|} \cdot \frac{A_{2 j}}{A_{0}} \\
& \cos \gamma_{j}=-\frac{\frac{\partial f}{\Delta t}\left(\vec{x}_{0}, t_{0}\right)}{\left|\nabla f\left(\vec{x}_{0}, t_{0}\right)\right|} \cdot \frac{A_{3 j}}{A_{0}}
\end{aligned}
$$




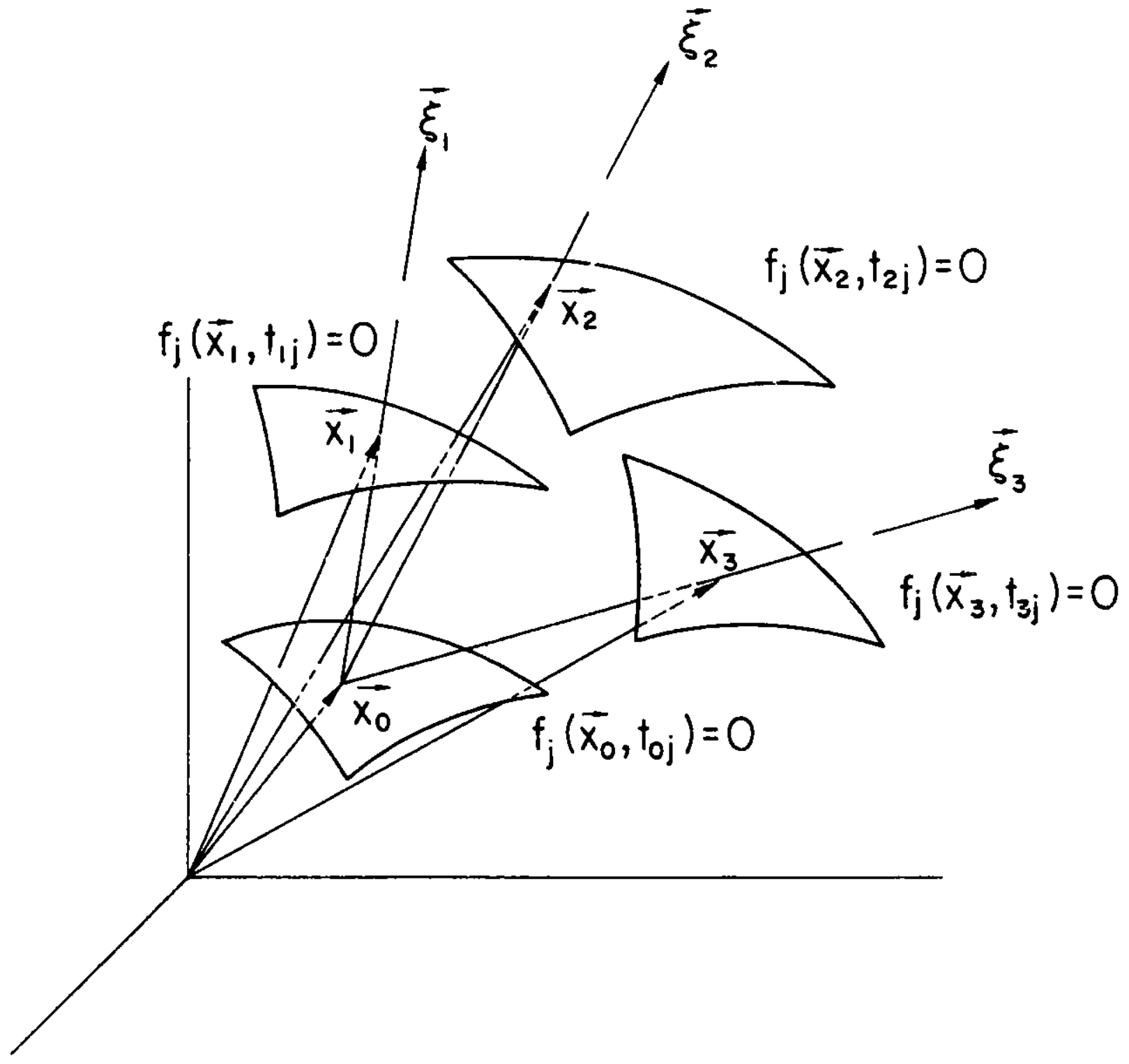

Fig. 2. Schematic of an Interface Passing Through Four Fixed
Locations in Space 
where

$A_{0}=\left|\begin{array}{ccc}\xi_{1 x} & \xi_{1 y} & \xi_{1 z} \\ \xi_{2 x} & \xi_{2 y} & \xi_{2 z} \\ \xi_{3 x} & \xi_{3 y} & \xi_{3 z}\end{array}\right|$

$A_{1 j}=\left|\begin{array}{lll}\frac{\Delta t_{1 j}}{s_{1}} & \xi_{1 y} & \xi_{1 z} \\ \frac{\Delta t_{2 j}}{s_{2}} & \xi_{2 y} & \xi_{2 z} \\ \frac{\Delta t_{3 j}}{s_{3}} & \xi_{3 y} & \xi_{3 z}\end{array}\right|$

$A_{2 j}=\left|\begin{array}{ccc}\xi_{1 x} & \frac{\Delta t_{1 j}}{s_{1}} & \xi_{1 z} \\ \xi_{2 x} & \frac{\Delta t_{2 j}}{s_{2}} & \xi_{2 z} \\ \xi_{3 x} & \frac{\Delta t_{3 j}}{s_{3}} & \xi_{3 z}\end{array}\right|$

and 


$$
A_{3 j}=\left|\begin{array}{ccc}
\xi_{1 x} & \xi_{1 y} & \frac{\Delta t_{1 j}}{s_{1}} \\
\xi_{2 x} & \xi_{2 y} & \frac{\Delta t_{2 j}}{s_{2}} \\
\xi_{3 x} & \xi_{3 y} & \frac{\Delta t_{3 j}}{s_{3}}
\end{array}\right|
$$

Making use of the definition of direction cosines, we obtain

$$
\frac{\left|\frac{\partial f}{\partial t}\left(\vec{x}_{0}, t_{0}\right)\right|}{\left|\nabla f_{j}\left(\vec{x}_{0}, t_{0}\right)\right|}=\left\{\frac{A_{1 j}^{2}+A_{2 j}^{2}+A_{3 j}^{3}}{A_{0}^{2}}\right\}^{-1 / 2}
$$

It follows from eqs. (25), (28), and (43) that

$$
\frac{1}{L_{s}}=\frac{\left|A_{0}\right|}{T} \sum_{j=1}^{N} \frac{1}{\sqrt{A_{1 j}^{2}+A_{2 j}^{2}+A_{3 j}^{2}}} .
$$

Equation (44) indicates that $1 / L_{s}$ can be unambiguously determined from three sets of measurements of $\Delta t_{k j}, k=1,2,3$.

\subsection{TECHNICAL APPROACH}

As discussed in the preceding section, there are two possible physical methods for determining the local specific interfacial area in a two-phase flow: one entails the detection of passage of interfaces through two fixed locations in the flow and the knowledge of the probability density function of the orientations of the interfaces at one of the two locations whereas the other requires only the detection of passage of interfaces through four fixed locations in the flow. The need to detect the passage of interfaces through fixed locations in the flow suggests the use of probing techniques. 
A number of probing techniques have been reported in the literature. They are based upon the fact that certain optical and electrical properties of fluids can be detected by miniature sensors. As these optical and electrical properties vary from one phase to another, a sudden change in the amplitude of the signals from the sensing probes would thus indicate the passage of a phase interface. Detailed reviews of optical and electrical probing techniques were given by Jones and Delhaye [36] and Bergles [37], respectively.

In the work reported here, an electrical resistivity probe technique is being developed for measurements of local specific interfacial areas in vertical gas-liquid bubbly flows. The electrical resistivity probe technique was proposed by Neal and Bankoff [38] for determination of bubble parameters in gas-liquid bubbly flows and has since been used by Park et a1. [39], Rigby et al. [40] for determination of bubble parameters in three-phase fluidized beds, by Hoffer and Resnick [41] for steady- and unsteady-state measurements in liquid-liquid dispersions, by Burgess and Calderbank [42] for measurement of bubble parameters in si gle-bubbly flow, by Serizawa et al. [43], Herringe and Davis [44] for study of structural development of gas-liquid bubbly flows, and by Veteau [24] for me. surement of local specific interfacial area. In principle, this technique consists of the instantaneous measurement of local electrical resistivity in the two-phase stream by means of a sensor electrode; the sensor is the exposed tip of an otherwise electrically insulated metal wire. The return electrode is the cupporting metal casing of the sensor. For purposes of simultaneous measurements at two locations in the flow, a doublesensor probe of the types shown in Fig. 3 has been used by several investigators $[39,40,43,44]$. Figure 4 shows the most commonly used configuration of the electrical circuitry, in which a probe (a pair of sensor and return electrodes) is connected in series with a DC power supply and one or more resistors to ground. In cases that a double-sensor probe was used, each of the two pairs of sensor and return electrodes was connected to its own measuring circuit $[39,40,43,44]$. Since the circuit is open or closed depending on whether the sensor is in contact with gas or liquid, the voltage drop across either the probe or one or more of the series resistors fluctuates between a $V_{\min }$ and a $V_{\max }$. Typical time-history records of signals from a double-sensor electrical resistivity probe [39] is shown in Fig. 5. One sees that the signals deviate from the ideal two-state square wave signals; this deviation is to a large measure due to the deformation of interface before the 


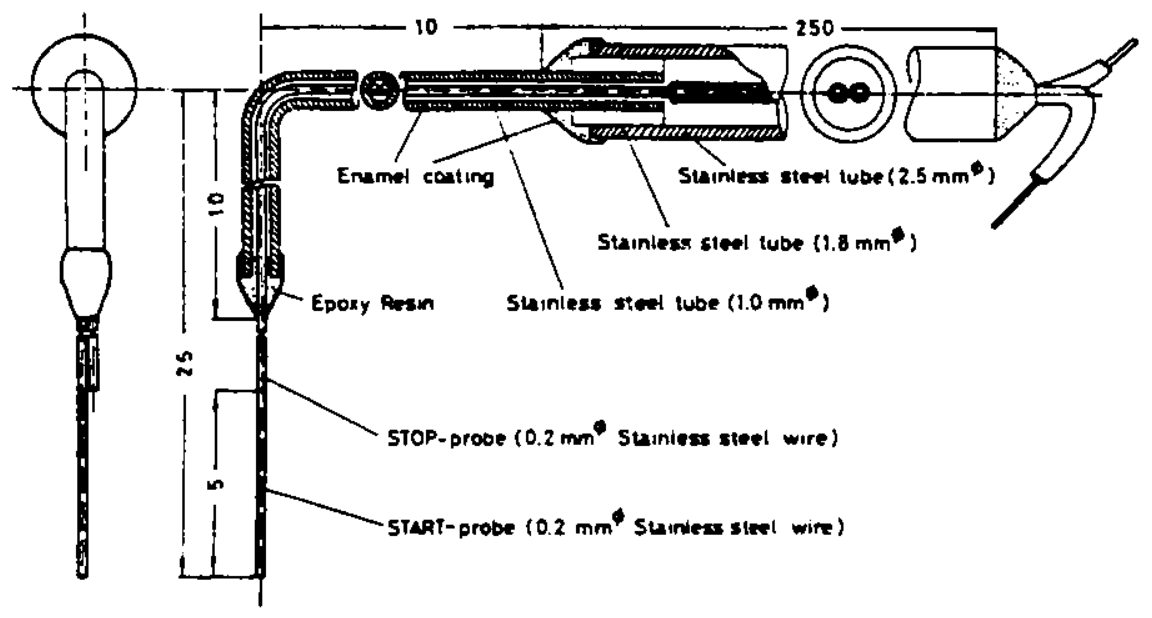

(a)

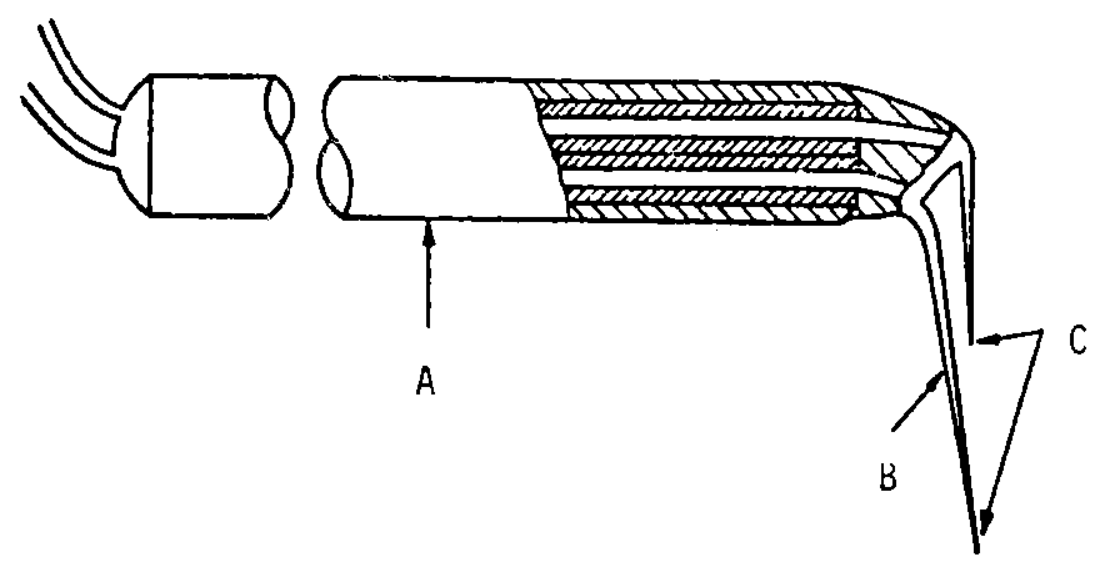

(b)

Fig. 3. Typical Double-Sensor Electrical Resistivity Probes (a) Reprinted with permission from Int. J. Multiphase Flow, Vol. 2, A. Serizawa et al., Turbulence structure of air-water bubbly flow - I. Measuring techniques, Copyright 1975, Pergamon Press plc.

(b) A. Stainless-steel Tube. B. Insulated Needles. c. Exposed Tips. Reprinted with permission from J.

Fluid Mech., Vol. 73, A. Herringe and M. R. Davis, Structural development of gas-liquid mixture flows, Copyright 1976, Cambridge University Press. 


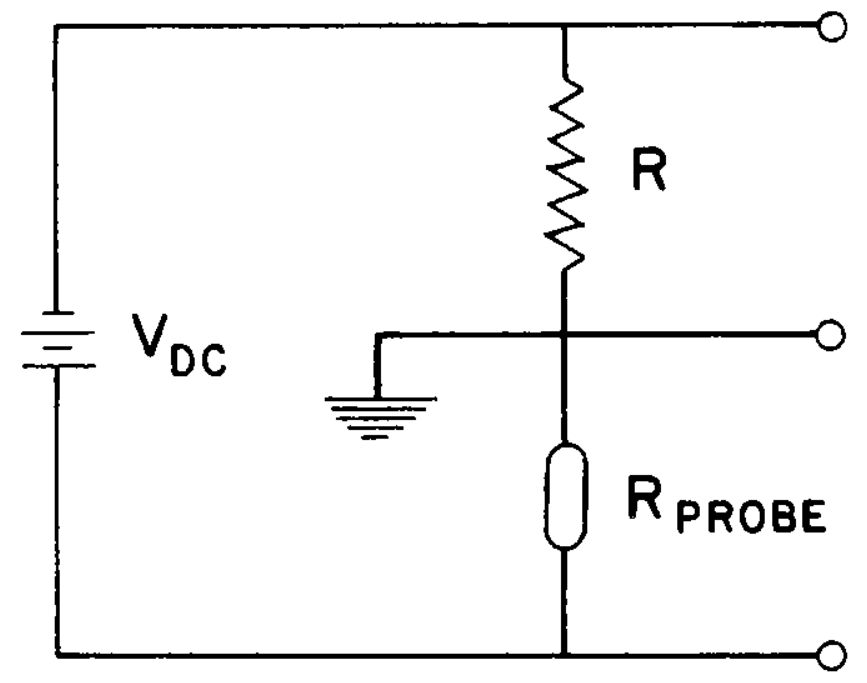

Fig. 4. Typical Configuration of Electrical Circuitry in the ElectricalResistivity-Probe Technique 


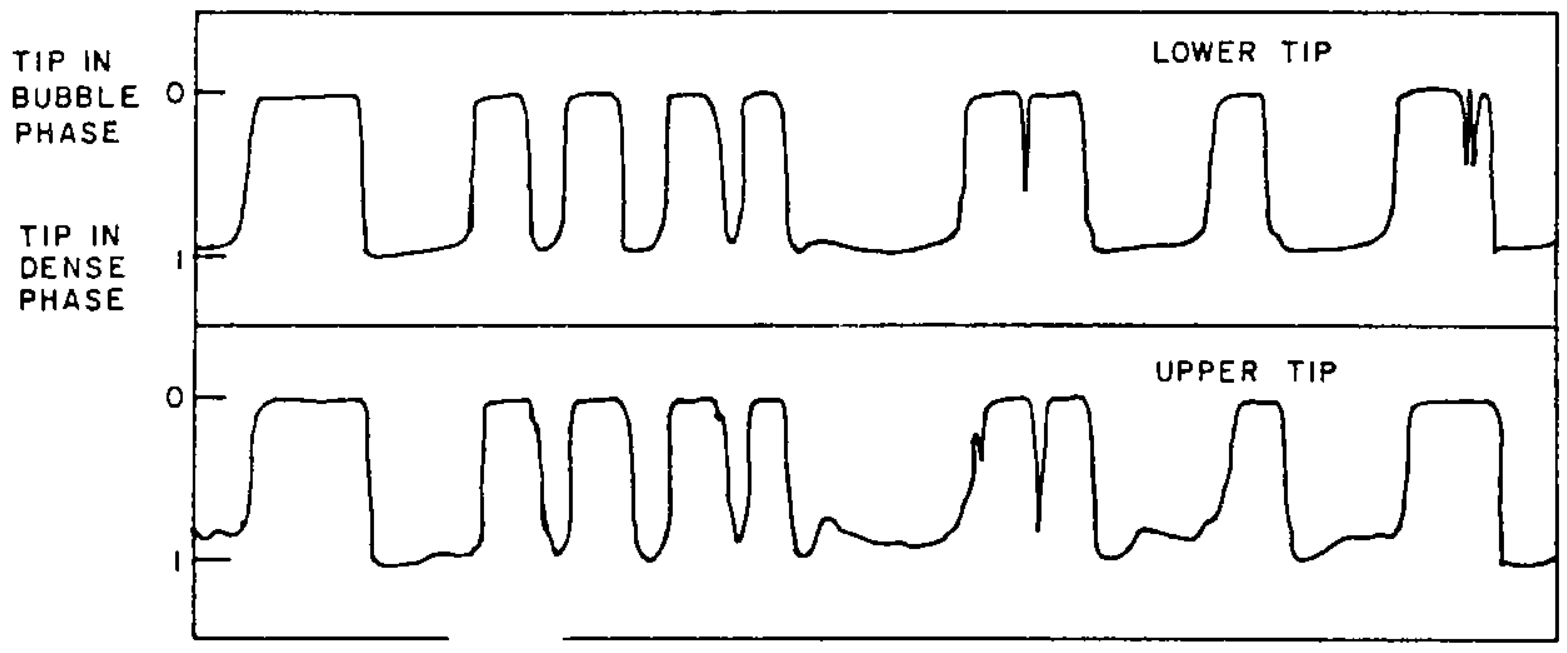

Fig. 5. Typical Time-History Records of Voltage Signals from a Double-Sensor Electrical Resistivity Probe Reproduced with permission from Chem. Eng. Sci., Vol. 24, W. H. Park et al., The properties of bubbles in fluidized beds of conducting particles as measured by an electroresistivity probe, Copyright 1969, Pergamon Press plc. 
sensor enters from one phase into the other phase. It is also seen that the trailing edges are generally steeper than the leading edges; this difference is probably due to the wetting of the sensor by the residual liquid when the sensor is in the gas phase. Such a signal can be either transformed into a two-state square wave signal by means of an on-line Schmidt trigger and then passed to other instruments for further on-line analysis $[41,43,44]$ or digitized and stored in an on-iine data acquisition microcomputer and then analyzed off-line [45]. Either approach of signal processing requires determination of a threshold voltage, which can be accomplished through comparison of void fraction thus obtained with that measured with other techniques. We note that the second approach obviates the experimental uncertainty associated with the electrochemical phenomena on the sensors and also enables us to preserve the raw signals. For these reasons, the second approach is chosen in this study.

\subsection{EXPERIMENTAL METHODS}

We consider first a gas-liquid bubbly mixture flowing upwards in a vertical test section made of circular pipes. A double-sensor electrical resistivity probe in which the line passing through the tips of the two sensors is parallel to the centerline of the test section is made to traverse along the diameter of the cross section as shown in Fig. 6 . The location of the tips of the two sensors are identified with the two fixed locations $\vec{x}_{0}$ and $\vec{x}_{1}$ considered in Section 3 ; in terms of cylindrical coordinates they are represented as $\vec{x}_{0}=\left(z_{0}, r^{(k)}\right)$ and $\vec{x}_{1}=\left(z_{1}, r^{(k)}\right)$ where $r(k)$ denotes a fixed radial coordinate which corresponds to the kth traversing stop of the probe. Suppose that there are a total of $M$ stops and that the sampling period at each stop remains constant at $T$ for an experimental run. Let $V_{0}^{(k)}(t)$ and $v_{1}^{(k)}(t)$ denote the time history records of signals from the two sensors at the kth stop; i.e.,

$$
\begin{aligned}
& v_{0}^{(k)}(t) \equiv v_{0}\left(z_{0}, r^{(k)}, t\right), t^{(k)}-\frac{T}{2} \leq t \leq t^{(k)}+\frac{T}{2}, \\
& v_{1}^{(k)}(t) \equiv v_{1}\left(z_{1}, r^{(k)}, t\right), t^{(k)}-\frac{T}{2} \leq t \leq t^{(k)}+\frac{T}{2},
\end{aligned}
$$



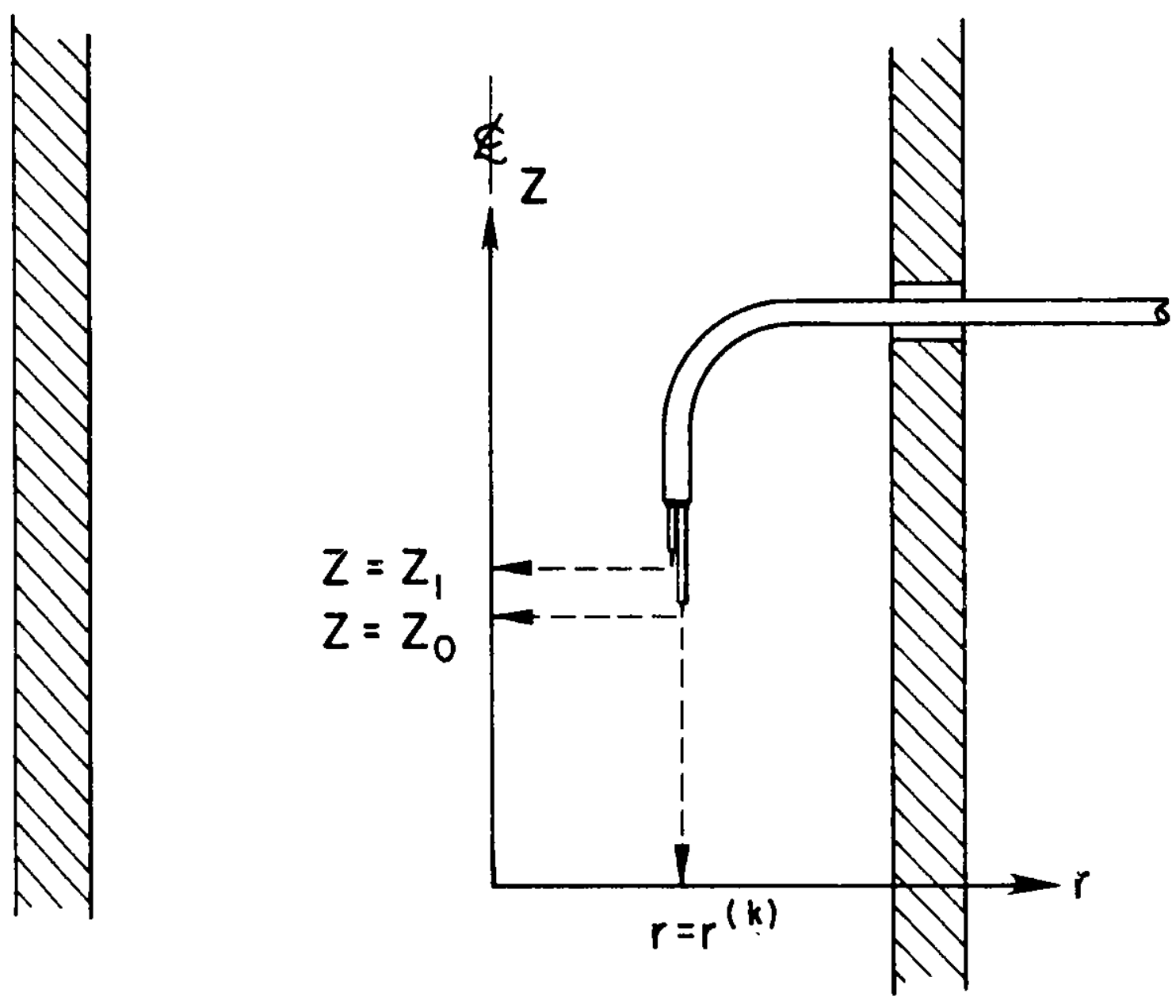

Fig. 6. Illustration of Coordinate System for Probe Traversal Configuration 
and let $V_{\text {oT }}$ denote a threshold voltage which applies to all $V_{o}^{(k)}, k=1$, $2, \ldots, M$ and $V_{1 T}$ denote a threshold voitage which applies to all $V_{1}^{(k)}, k=1$, $2, \ldots, M$.

As shown in Fig. 7, the gas-contact period of a sensor over the sampling period $T$ is a function of the threshold voltage associated with that sensor. Consequently, the local void fractions $\alpha_{0}(k)$ and $\alpha_{1}(k)$, which are defined as

$$
\alpha_{0}^{(k)} \equiv a_{0}\left(z_{0}, r^{(k)}, t^{(k)}\right)=\frac{1}{T} \sum_{j=1}^{N-1}\left(t_{o j+1}^{(k)}-t_{o j}^{(k)}\right)
$$

and

$$
\alpha_{1}^{(k)} \equiv \alpha_{1}\left(z_{0}, r^{(k)}, t^{(k)}\right)=\frac{1}{T} \sum_{j=1}^{N-1}\left(t_{1 j+1}^{(k)}-t_{1 j}^{(k)}\right),
$$

are functions of the threshold voltages $V_{0 T}$ and $V_{1 T}$, respectively. Furthermore, when the process is ergodic, which is assumed to be the case, $a_{0}(k)$ and $\alpha_{1}^{(k)}$ do not depend upon $t(k)$ so they can be averaged over the radial position to give line-averaged void fractions

$$
\begin{aligned}
& \left.<\alpha_{0}\right\rangle_{1}=\frac{1}{2} \sum_{k=1}^{M-1}\left(r^{(k+1)}-r^{(k)}\right) \cdot\left(a_{0}^{(k+1)}-a_{0}^{(k)}\right) \\
& <\alpha_{1}>1=\frac{1}{2} \sum_{k=1}^{M-1}\left(r^{(k+1)}-r^{(k)}\right) \cdot\left(\alpha_{1}^{(k+1)}-\alpha_{1}^{(k)}\right) .
\end{aligned}
$$

The line-average void fractions $\left\langle a_{0}\right\rangle_{1}$ and $\left\langle\alpha_{1}\right\rangle_{1}$ thus obtained are also functions of the threshold voltages $V_{0 T}$ and $V_{1 T}$, respectively, which can be adjusted through software until agreement between $\left\langle\alpha_{0}\right\rangle_{1},\left\langle_{1}\right\rangle_{1}$ and the lineaveraged void fractions obtained concurrently by means of one of the photon 


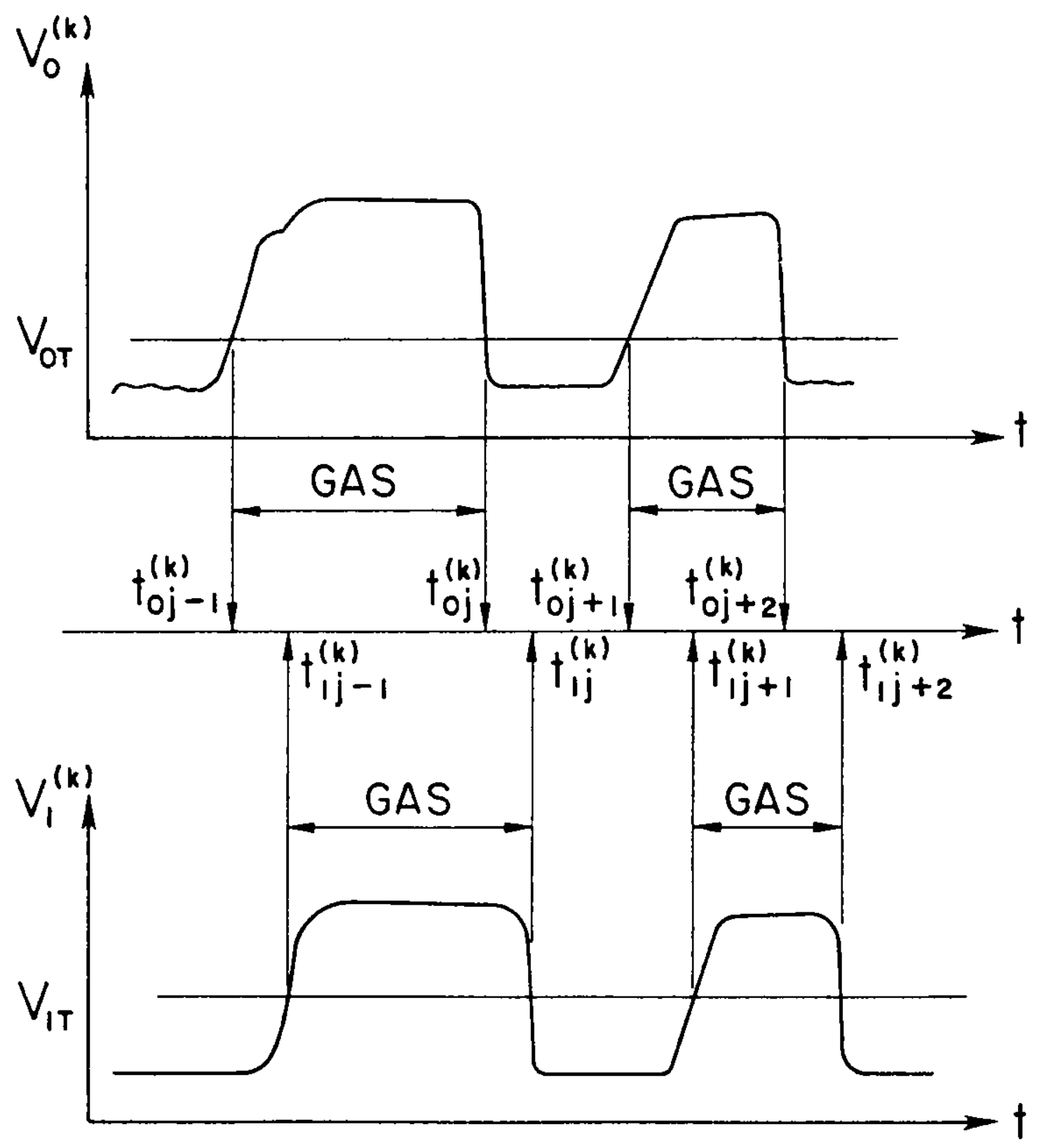

Fig. 7. Definition of Parameters Pertinent to Data Analysis 
attenuation techniques is reached. In regions where the flow is fully developed, the volume averaged void fractions are identical to the lineaverage ones; the adjustment of $V_{0 T}$ and $V_{1 T}$ can be based on the comparison between $\left\langle\alpha_{0}\right\rangle_{1},\left\langle\alpha_{1}\right\rangle_{1}$ and the volume-averaged void fraction calculated from concurrent differential pressure measurements. Specifically, the method of adjustment consists of an iterative scheme for approximating the roots of the nonlinear equations

$$
\left.F_{0}\left(V_{0 T}\right) \equiv<\alpha_{0}\right\rangle_{1}\left(V_{0 T}\right)-\alpha_{0}>_{\exp }=0
$$

and

$$
\left.\left.F_{1}\left(V_{1 T}\right) \equiv<\alpha_{1}\right\rangle_{1}\left(V_{1 T}\right)-<\alpha_{1}\right\rangle_{\exp }=0
$$

In view of the fact that $V_{\min }<V_{0 T}<V_{\max }$ and $V_{\min }<V_{1 T}<V_{\max }$, we use the regula faisi method for finding the desired $V_{0 T}$ and $V_{1 T}$.

Once $V_{O T}$ and $V_{1 T}$ are determined, $t_{0 j}$ and $t_{1 j}(j=1, \ldots N)$ are determined and the local specific interfacial area can be calculated with the help of eq. (36). When the two-phase flow under study is not in the bubbly-flow regime, the assumptions underlying eq. (36) can no longer be justified and only the arguments leading to eq. (44) hold. Consequently, a quadruple-sensor electrical resistivity probe instead of a double-sensor one is called for in measurement of local specific interfacial area in such a flow. The time history records of signals from the four sensors can be processed in a manner analogous to those described in the preceding paragraphs for the case in which a double-sensor probe is used.

Recall that eqs. (36) and (44) are derived based on the assumption that $s_{k}$ and $\Delta t_{k j}(k=1,2,3)$ are small in comparison with the length scale and the time scale, respectively. It is worthwhile at this point to make some remarks about the conditions under which the assumption can be justified. The length scale and the time scale are, of course, characteristic quantities associated with the physical system under consideration. In accordance with the basic concept of the two-fluid model, we consider a physical dimension which characterizes the degree of dispersion or degree of separation as the length scale, e.g., typical bubble diameter in the case of bubbly flow and 
typical liquid film thickness in the case of annular flow, and consider the time scale as a measure of the time it takes for the two-phase mixture to travel a distance equal to the length scale. Thus a bubbly flow with bubbles of diameter on the order of $1 \mathrm{~mm}$ entails a probe in which the distances between the tips of sensors are on the order of $0.1 \mathrm{~mm}$. When the distances $s_{k}$ are fixed to be on the order of $1 \mathrm{~mm}$, the diameters of bubbles should be on the order of $1 \mathrm{~cm}$ for the probing technique for measuring local specific interfacial area to be applicable. 


\section{REFERENCES}

1. Ishii, M., Thermo-fluid Dynamic Theory of Two-Phase Flow, Eyrolles, Paris, 1975, pp. 99, $145 \mathrm{ff}$.

2. Kataoka, I., Ishi i, M., and Serizawa, A., "Local Formulation and Measurements of Interfacial Area Concentration in Two-Phase Flow," Int 1. J. of Multiphase Flow, Vol. 12, 1986, pp. 505-529.

3. Bergles, A. E., Collier, J. G., Delhaye, J. M., Hewitt, G. F., Mayinger, $F$., Two-Phase Flow and Heat Transfer in the Power and Process Industries, Hemisphere, Washington, 1981, pp. 76ff.

4. Kasturi, G. and Stepanek, J. B., "Two-Phase Flow - III. Interfacial Area in Cocurrent Gas-Liquid Flow," Chem. Eng. Sci., Vol. 29, 1974, pp. 713719.

5. Robinson, C. W. and Wilke, C. R., "Simultaneous Measurement of Interfacial Area and Mass Transfer Coefficients for a Well-Mixed Gas Dispersion in Aqueous Electrolyte Solutions," AIChE J., Vol. 20, 1974, pp. 285294.

6. Sridharan, K. and Sharma, M. M., "New Systems and Methods for the Measurement of Effective Interfacial Area and Mass Transfer Coefficients in Gas-Liquid Contactors," Chem. Eng. Sci., Vol. 31, 1976, pp. 767-774.

7. Landau, J., Boyle, J., Gomaa, H. G., and Al Taweel, A. M., "Comparison of Methods for Measuring Interfacial Areas in Gas-Liquid Dispersions," Canadian J. of Chem. Eng., Vol. 55, 1977, pp. 13-18.

8. Shilimkan, R. V. and Stepanek, J. B., "Interfacial Area in Cocurrent GasLiquid Upward Flow in Tubes of Various Size," Chem. Eng. Sci., Vol. 32, 1977 , pp. 149-154.

9. Shilimkan, R. V. and Stepanek, J. B., "Mass Transfer in Cocurrent GasLiquid Flow: Gas Side Mass Transfer Coefficients in Upflow, Interfacial Areas and Mass Transfer Coefficient in Gas and Liquid in Downflow," Chem. Eng. Sci., Vol. 33, 1978, pp. 1675-1680.

10. Sridhar, T. and Potter, 0. E., "Interfacial Area Measurements in GasLiquid Agitated Vessels, Comparison of Techniques," Chem. Eng. Sci., Vol. 33, 1978, pp. 1347-1353.

11. Watson, A. P., Cormack, D. E., and Charles, M. E., "A Preliminary Study of Interfacial Areas in Vertical Cocurrent Two-Phase Upflow, "Canadian J. of Chem. Eng., Vol. 57, 1979, pp. 16-23.

12. Dhanuka, V. R. and Stepanek, J. B., "Simultaneous Measurement of Interfacial Area and Mass Transfer Coefficient in Three-Phase Fluidized Beds," AIChE J., Vol. 26, 1980, pp. 1029-1038.

13. Farritor, R. E. and Hughmark, G. A., "Interfacial Area and Mass Transfer with Gas-Liquid Systems in Turbine-Agitated Vessels," Chem. Eng. Com., Vol. 4, 1980, pp. 143-147. 
14. Hassan, I. T. M. and Robinson, C. W., "Mass-Transfer-Effective Bubble Coalescence Frequency and Specific Interfacial Area in a Mechanically Agitated Gas=Liquid Contactor," Chem. Eng. Sci., Vol. 35, 1980, pp. 12771289.

15. Vavruska, J. S. and Perona, J. J., "Measurements of Interfacial Areas in Cocurrent Gas-Liquid Downward Flow," Canadian J. of Chem. Eng., Vol. 58, 1980, pp. 141-144.

16. Schumpe, A. and Deckwer, W.-D., "Comparison of the Photographic and the Sulfite Oxidation Method for Interfacial Area Determination in Bubble Columns," Chem. Eng. Com., Vol. 17, 1982, pp. 313-324.

17. Kulkarmi, A., Shah, Y., and Schumpe, A., "Hydrodynamics and Mass Transfer in Downflow Bubble Column," Chem. Eng. Com., Vol. 24, 1983, pp. 307-337.

18. Capuder, E. and Koloini, T., "Gas Hold-up and Interfacial Area in Aerated Suspensions of Small Particles," Chem. Eng. Res. \& Design, Vol. 62, 1984, pp. $255-260$.

19. Nagy, E., Borlai, 0., Laurent, E., and Charpentier, J.-C., "Determination of the Gas-Liquid Interfacial Area of a Perforated Plate Operating with Cross Flow," Int1. Chem. Eng., Vol. 26, 1986, pp. 637-646.

20. Sharma, M. M. and Danckwerts, P. V., "Chemical Methods of Measuring Interfacial Area and Mass Transfer Coefficients in Two-Fluid Systems," British Chem. Eng., Vol. 15, 1970, pp. 522-528.

21. Danckwerts, P. V., Gas-Liquid Reactions, McGraw-Hill, New York, 1970, pp. $111 \mathrm{ff}$.

22. Schumpe, A. and Deckwer, W.-D., "Analys is of Chemical Methods for Determination of Interfacial Areas in Gas-in-Liquid Dispersions with Nonuniform Bubble Sizes," Chem. Eng. Sci., Vol. 35, 1980, pp. 2221-2233.

23. Akita, K. and Yoshida, F., "Bubble Size, Interfacial Area, and LiquidPhase Mass Transfer Coefficient in Bubble Columns," Ind. and Eng. Chem., Process Design and Development, Vol. 13, 1974, pp. 84-91.

24. Veteau, J.-M., "Contribution á l'Études des, Techniques de Mesure de l'Aire Interficiale dans les Écoulements à Bulles," Sc.D. Thesis, Nationa 1 Grenoble Polytechnic Institute, France, 1981.

25. Jeng, J. J., Jer, R. M., and Yang, Y. M., "Surface Effects and Mass Transfer in Bubble Column," Ind. and Eng. Chem., Process Design and Development, Vol. 25, 1986, pp. 974-978.

26. Yang, N. S., Shen, Z.-Q., Chen, B. H., and McMillan, A. F., "Pressure Drop, Gas Holdup, and Interfacial Area for Gas-Liquid Contact in Karr Columns," Ind. and Eng. Chem., Process Design and Development, Vol. 25, 1986, pp. 660-664. 
27. Calderbank, P. H., "Physical Rate Processes in Industrial Fermentation, Part I: The Interfacial Area in Gas-Liquid Contacting with Mechanical Agitation," Trans. of the Inst. of Chem. Engineers, Vol. 36, 1958, pp. 443-463.

28. McLaughlin, C. M. and Rushton, J. H., "Interfacial Areas of Liquid-Liquid Dispersions from Light Transmission Measurements," AlChE J., Vol. 19, 1973, pp. 813-822.

29. Sridhar, T. and Potter, 0. E., "Interfacial Areas in Gas-Liquid Stirred Vessels," Chem. Eng. Sci., Vol. 35, 1980, pp. 683-695.

30. Stravs, A. A. and von Stockar, U., "Measurement of Interfacial Areas in Gas-Liquid Dispersions by Ultrasonic Pulse Transmission," Chem. Eng. Sci., Vol. 40, 1985, pp. 1169-1175.

31. Stravs, A. A., Pittet, A., von Stockar, U., and Reilly, P. J., "Measurement of Interfacial Areas in Aerobic Fermentations by Uitrasonic Pulse Transmission," Biotechnology and Bioengineering, Vol. 28, 1986, pp. 13021309.

32. Bensler, H. P., Delhaye, J.-M., and Favreau, C., "Measurement of Interfacial Area in Bubbly Flows By Means of an Ultrasonic Technique," paper presented at the 24th ASME/AIChE Nat1. Heat Trans. Conf., Pittsburgh, Pennsylvania, August 9-12, 1987.

33. Marston, P. L., Langley, D. S., and Kingsbury, D. L., "Light Scattering by Bubbles in Liquids: Mie Theory, Physical-Optics Approximation, and Experiments," App 7. Sci. Res., Vol. 38, 1982, pp. 373-383.

34. Nishi, R., "The Scattering and Absorption of Sound Waves by a Gas Bubble in a Viscous Liquid," Acustica, Vol. 33, 1975, pp. 65-74.

35. Banerjee, S. and Khachadour, A., "A Radioisotope Method for Interfacial Area Measurements in Two-Component Systems," J. of Heat Trans., Vo1. 103, 1981, pp. 319-324.

36. Jones, Jr., 0. C. and Delhaye, J.-M., "Transient and Statistical Measurement Techniques for Two-Phase Flows: A Critical Review," Intl. J. of Multiphase Flow, Vol. 3, 1976, pp. 89-116.

37. Bergles, A. E., "Electrical Probes for Study of Two-Phase Flows," in TwoPhase Flow Instrumentation, edited by Le Tourneau, B. W. and Bergles, A. E., ASME, New York, 1968, pp. 70-81.

38. Neal, L. G. and Bankoff, S. G., "A High Resolution Resistivity Probe for Determination of Local Void Properties in Gas-Liquid Flow," AIChE J., Vol. 9, 1963, pp. 490-494.

39. Park, W. H., Kang, W. K., Capes, C. E., and Osberg, G. L., "The Properties of Bubbles in Fluidized Beds of Conducting Particles as Measured by an Electroresistivity Probe," Chem. Eng. Sci., Vol. 24, 1969, pp. 851865. 
40. Rigby, G. R., van Blockland, G. P., Park, W. H., and Capes, C. E., "Properties of Bubbles in Three Phase Fluidized Beds as Measured by an Electroresistivity Probe," Chem. Eng. Sci., Vol. 25, 1970, pp. 1729-1741.

41. Hoffer, M. S. and Resnick, W., "A Modified Electroresistivity Probe Technique for Steady- and Unsteady-State Measurements in Fine Dispersions - I. Hardware and Practical Operating Aspects," Chem. Eng. Sci., Vol. 30, 1975, pp. 473-480.

42. Burgess, J. M. and Calderbank, P. H., "The Measurement of Bubble Parameters in Two-Phase Dispersions - I. The Development of an Improved Probe Technique," Chem. Eng. Sci., Vol. 30, 1975, pp. 743-750.

43. Serizawa, A., Kataoka, I., and Michiyoshi, I., "Turbulence Structure of Air-Water Bubbly Flow - I. Measuring Techniques," Intl. J. of Multiphase Flow, Vol. 2, 1975, pp. 221-233.

44. Herringe, R. A. and Davis, M. R., "Structural Development of Gas-Liquid Mixture Flows," J. of Fluid Mechanics, Vol. 73, 1976, pp. 97-123.

45. Wang, S. K., "Three-Dimensional Turbulence Structure Measurements in Air/ Water Two-Phase Flow," Ph.D. Thesis, Rensselaer Polytechnic Institute, Troy, New York, 1985. 
Distribution for MFRI-4 (ANL-89/5)

\section{Internal:}
H. Drucker
J. F. Marchaterre
A. J. Goldman
L. W. Deitrich
D. Rose
D. H. Cho
B. W. Spencer

\author{
W. T. Sha (5) \\ M. J. Tan (20) \\ ANL Patent Department \\ ANL Contract File \\ ANL Libraries \\ TIS Files (3)
}

\section{External:}

DOE-OSTI, for distribution per UC-406 (53)

Manager, Chicago Operations Office, DOE

O. P. Manley, DOE, Office of Basic Engineering Sciences (5)

M. Ishii, Purdue University, West Lafayette, IN 47907 (20)

J. P. Hartnett, Midwest University Energy Consortium, Chicago, IL 60680 (5)

G. Kocamustafaogullari, Univ. of Wiscons in-Milwaukee, Milwaukee, WI 53201

T. J. Hanratty, Univ. of Illinois-Urbana-Champaign, Urbana, IL 61801 